\title{
VALIDAÇÃO DO MODELO DE ELETROCOAGULAÇÃO FLOTAÇÃO NO TRATAMENTO DE EFLUENTE TÊXTIL VISANDO À REMOÇÃO DE DQO, UTILIZANDO REATOR EM BATELADA.
}

\author{
T. C. PARENTE ${ }^{1}$, R.V.SAWAKI ${ }^{1}$, J.E.C. ALEXANDRE ${ }^{2}$, A.C. LIMA $^{3}$, J.P. RIBEIRO ${ }^{3}$, \\ E.F.ABDALA NETO², R.F. NASCIMENTO ${ }^{3}$ \\ ${ }^{1}$ Universidade Federal do Ceará, Departamento de Engenharia Química \\ ${ }^{2}$ Universidade Federal do Ceará, Departamento de Engenharia Hidráulica e Ambiental \\ ${ }^{3}$ Universidade Federal do Ceará, Departamento de Química Analítica \\ E-mail para contato: taiscoutinhop@gmail.com
}

\begin{abstract}
RESUMO - O tratamento de efluentes têxteis tem se tornado preocupação da maioria das indústrias, pois o mesmo deve ser descartado seguindo as normas ambientais. A eletrocoagulação-flotação ganha força dentro das técnicas não convencionais por sua elevada eficiência operacional, custo reduzido e atuação efetiva em moléculas de corantes. Nesse trabalho, avaliaremos a eficiência de remoção da matéria orgânica em termos de DQO (demanda química de oxigênio) utilizando eletrodos de aço inoxidável. $\mathrm{O}$ experimento foi realizado em um reator em batelada e o modelo foi validado utilizando os softwares R 3.0.3 e ipython notebook 3.4.2. Os resultados experimentais obtidos mostraram uma remoção de $89,38 \%$ de DQO em 60 minutos, enquanto o modelo teórico mostrou uma remoção de $87,95 \%$ para o mesmo tempo de processo.
\end{abstract}

\section{INTRODUÇÃO}

A agressividade ao meio ambiente vem aumentando progressivamente à medida que ocorre o acelerado crescimento populacional e o aumento da atividade industrial. Dentro deste contexto, o setor têxtil apresenta especial destaque, devido à elevada demanda de água exigida em seus processos e a consequente geração de grandes volumes de efluentes. (MEDEIROS, 2011). Os efluentes gerados no processamento têxtil são de difícil degradação devido à presença de moléculas de corantes, possuindo elevada recalcitrância. Quando lançados sem tratamento adequado provocam danos à vida aquática e à saúde humana.

Com essa preocupação, surgem diversos tratamentos para efluentes têxteis como adsorção, coagulação - flotação, degradação química e processos oxidativos avançados. A eletrocoagulação - flotação vem se destacando por ser uma tecnologia versátil, de simples aplicação e que atua em moléculas dissolvidas, além de moléculas suspensas. Diferente da coagulação - flotação convencional que atua apenas sobre materiais suspensos, não degradando os corantes. Os elétrons são oriundos diretamente do efluente, eliminando a necessidade da adição de substâncias oxidantes ou redutoras potencialmente tóxicas. 
No processo de eletrocoagulação - flotação (ECF), o coagulante $\left(\mathrm{M}^{\mathrm{n}+}\right)$ provém da oxidação dos eletrodos utilizados, como mostra a equação 1, ocasionando a neutralização das cargas superficiais das partículas coloidais e suspensas, desestabilizando-as. A aglutinação das partículas desestabilizadas pelos hidróxidos metálicos $\left(\mathrm{Mn}(\mathrm{OH})_{\mathrm{n}}\right)$ proporciona o crescimento dos flocos. Paralelamente, a partir da hidrólise da água, ocorre a formação de microbolhas de gás oxigênio e hidrogênio, como mostrados na equação 2 e 4, que, por arraste, ascendem à superfície juntamente com os flocos formados, realizando a flotação e, consequentemente, clarificando o efluente. Seguem as reações do exposto acima:

$$
\begin{aligned}
& M_{(s)} \rightarrow M_{(a q)}^{n+}+n e^{-} \\
& 2 \mathrm{H}_{2} \mathrm{O}_{(L)} \rightarrow 4 \mathrm{H}_{(a q)}^{+}+O_{2(g)}+4 e^{-} \\
& M_{(a q)}^{n+}+n e^{-} \rightarrow M_{(s)} \\
& 2 \mathrm{H}_{2} \mathrm{O}_{(L)}+2 e^{-} \rightarrow H_{2(g)}+2 \mathrm{OH}^{-}
\end{aligned}
$$

O presente trabalho tem como objetivo avaliar a redução da concentração de matéria orgânica em termos de DQO em efluente têxtil aplicando o processo de ECF com eletrodos de aço inoxidável, como também validar o modelo utilizado através da simulação do processo em reator batelada.

\section{METODOLOGIA}

\subsection{Ensaios de eletrocoagulação-flotação (ECF)}

O processo eletrolítico foi promovido por corrente contínua pulsada utilizando-se de uma fonte de tensão 220-13,8 V (Hayama ${ }^{\circledR} \mathrm{HY}-125^{\mathrm{TM}}$ ). As reações foram conduzidas em um reator cilíndrico (diâmetro $=10 \mathrm{~cm}$ e altura $=60 \mathrm{~cm}$ ) operando em batelada conforme ilustrado na figura 1. O conjunto de cátodos e ânodos empregados foi composto por quatro placas de aço inoxidável, conectadas por arranjo bipolar em paralelo, cada uma medindo $5 \mathrm{x}$ 40 x $0,3 \mathrm{~cm}$, resultando em uma área total de $800 \mathrm{~cm}^{2}$. Os eletrodos foram dispostos com espaçamento de $1 \mathrm{~mm}$ entre si. A velocidade de agitação e a frequência do experimento foram $200 \mathrm{rpm}$ e $600 \mathrm{~Hz}$, respectivamente. Esses valores foram obtidos a partir de um estudo de otimização do processo anteriormente realizado, logo os mesmos foram escolhidos para a realização da validação do modelo do reator em batelada.

Para a realização dos ensaios ECF foi utilizado um volume de dois litros e seicentos mililitros de efluente e coletadas amotras a cada dez minutos durante 60 minutos. $\mathrm{O}$ experimento foi realizado em duplicata.

Figura 1 - Diagrama experimental do reator.

Fonte: MAIA et al. (2014) 

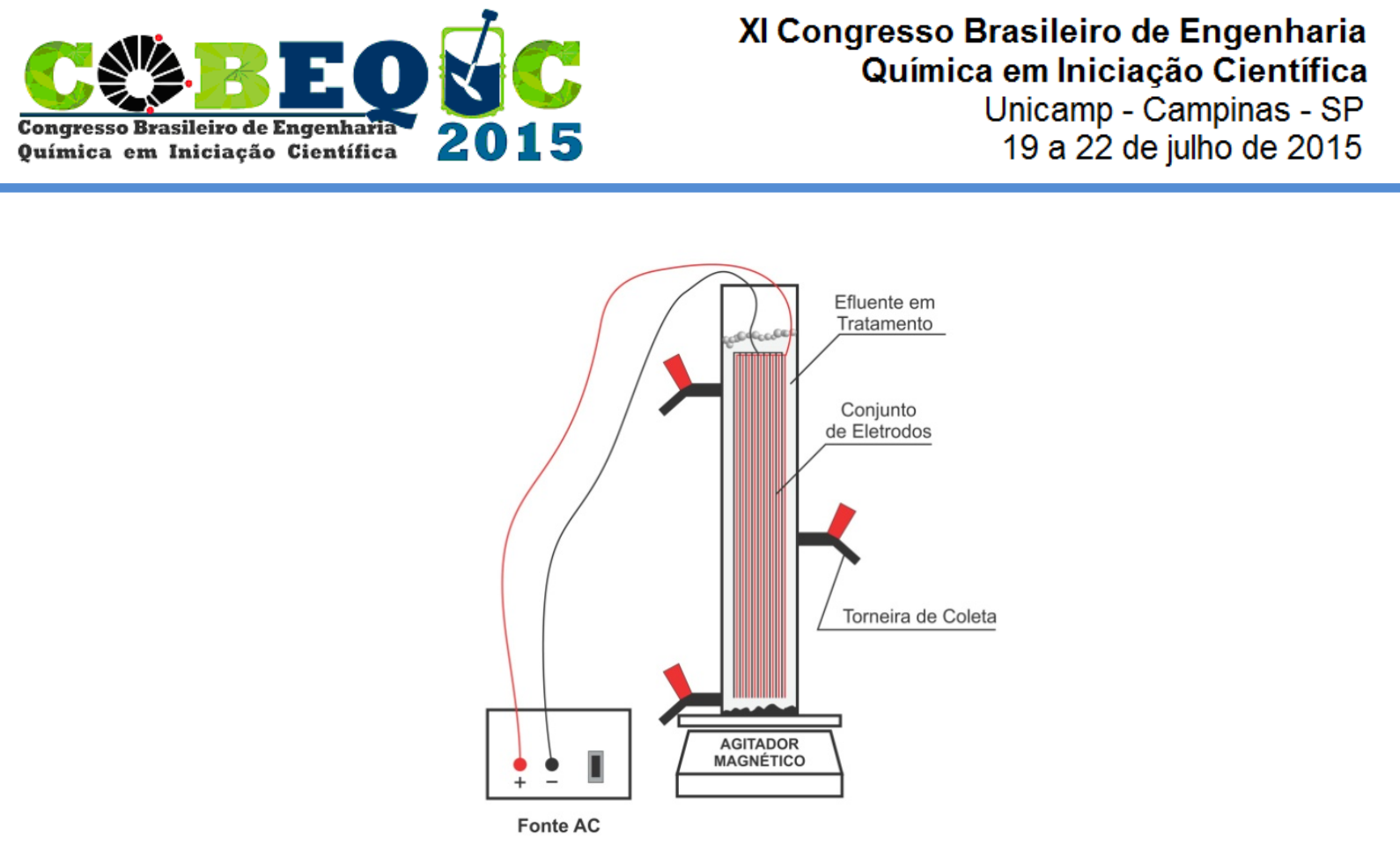

\subsection{Demanda Química de Oxigênio (DQO)}

A análise de demanda química de oxigênio foi realizada segundo metodologias descritas no Standard Methods for the Examination of Water and Wastewater. (APHA, 2005). As amostras foram coletadas, centrifugadas (4000 rpm durante cinco minutos) e diluídas (1:5) antes da adição das soluções digestoras e catalíticas. Em seguida, foram postas em um bloco digestor à $150^{\circ} \mathrm{C}$ por duas horas e submetidas à leitura da absorbância no espectrofotômetro Shimadzu ${ }^{\circledR} U V$ - vis 1800 no comprimento de onda de $420 \mathrm{~nm}$.

\subsection{Modelagem e simulação do processo eletrolítico}

O percentual de remoção de DQO foi analisado a partir de um estudo de cinética de degradação para os tempos experimentais. Para tal, utilizou-se o software R versão 3.0.3 pelo método do ajuste de regressão não linear. Os dados de cinética foram então inseridos em balanço de massa para um reator em batelada, realizando a modelagem e simulação do processo no software ipython notebook versão 3.4.2. Os resultados teóricos foram comparados com os dados experimentais.

\section{RESULTADOS E DISCUSSÃO}

A tabela 1 ilustra os valores obtidos de DQO em mg $\mathrm{O}_{2}$ por litro em cada tempo de processo. Nota-se que ocorre a diminuição da DQO ao longo do tratamento, como esperado, obtendo uma redução de $89,38 \%$.

Tabela 1 - Resultados obtidos de Demanda Química de Oxigênio.

\begin{tabular}{cccccccc}
\hline $\begin{array}{c}\text { Tempo } \\
(\min )\end{array}$ & 0 & 10 & 20 & 30 & 40 & 50 & 60 \\
\hline
\end{tabular}


DQO $1 \quad 808,64$

$\left(\mathrm{mgO}_{2} / \mathrm{L}\right)$

DQO 1.1

808,64

313,18

240,45

205,23

187,05

121,14

84,77

$$
315,45
$$

229,09

209,77

$183,64 \quad 125,68$

87,05

Os dados experimentais foram então tratados pelo método de ajuste de regressão não linear obtendo um modelo de cinética de segunda ordem. $\mathrm{O}$ valor da constante de velocidade de reação k obtido foi de $0,0001504726 \mathrm{~L} \mathrm{mg}^{-1} \mathrm{~min}^{-1}$ ou $\mathrm{k}=4,8 \mathrm{~L} \mathrm{~mol}^{-1} \mathrm{~min}^{-1}$ mostrado na figura 2 abaixo, gerado pelo software R 3.0.3.

Figura 2 - Gráfico do modelo de ajuste de regressão não linear.

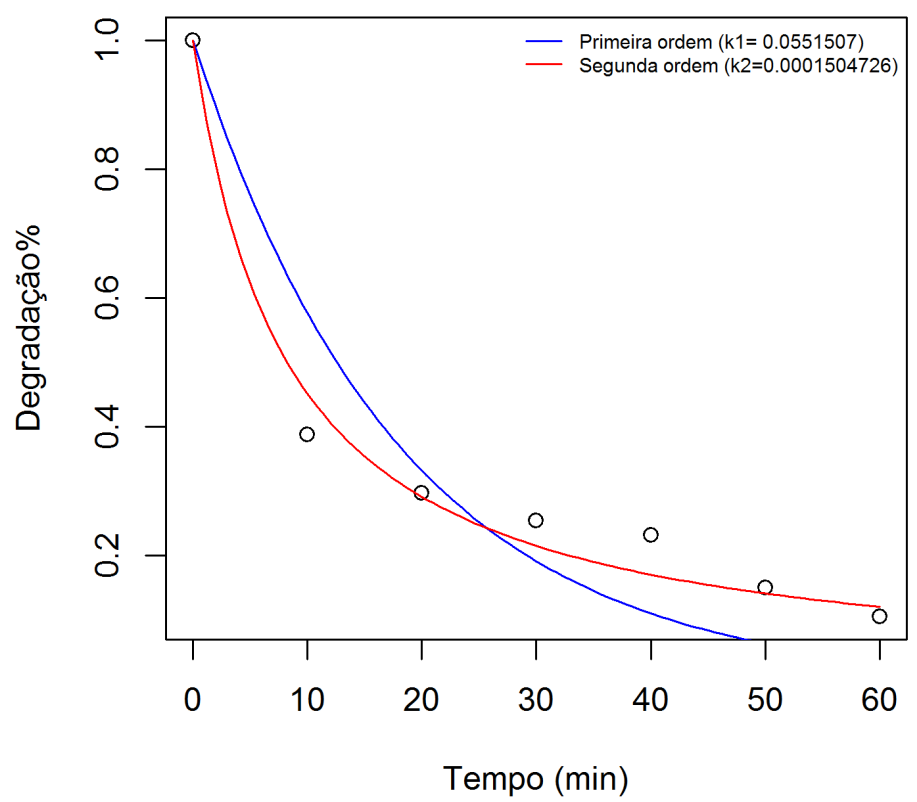

A modelagem do reator foi realizada tomando como base a concentração de oxigênio consumido nas amostras coletadas. Desse modo, aplicou-se um balanço de massa para sistema em batelada, equação 5, juntamente com o valor da constante de velocidade de reação no software ipython notebook 3.4.2. As condições iniciais utilizadas foram a DQO no efluente bruto e o tempo inicial. A figura 3 explana os pontos experimentais de DQO com barras de erro e a curva de DQO teórica.

$$
\frac{d C_{A}}{d t}=-k * C_{A}^{2}
$$

Figura 3 - Gráfico de pontos experimentais de DQO e curva teórica. 

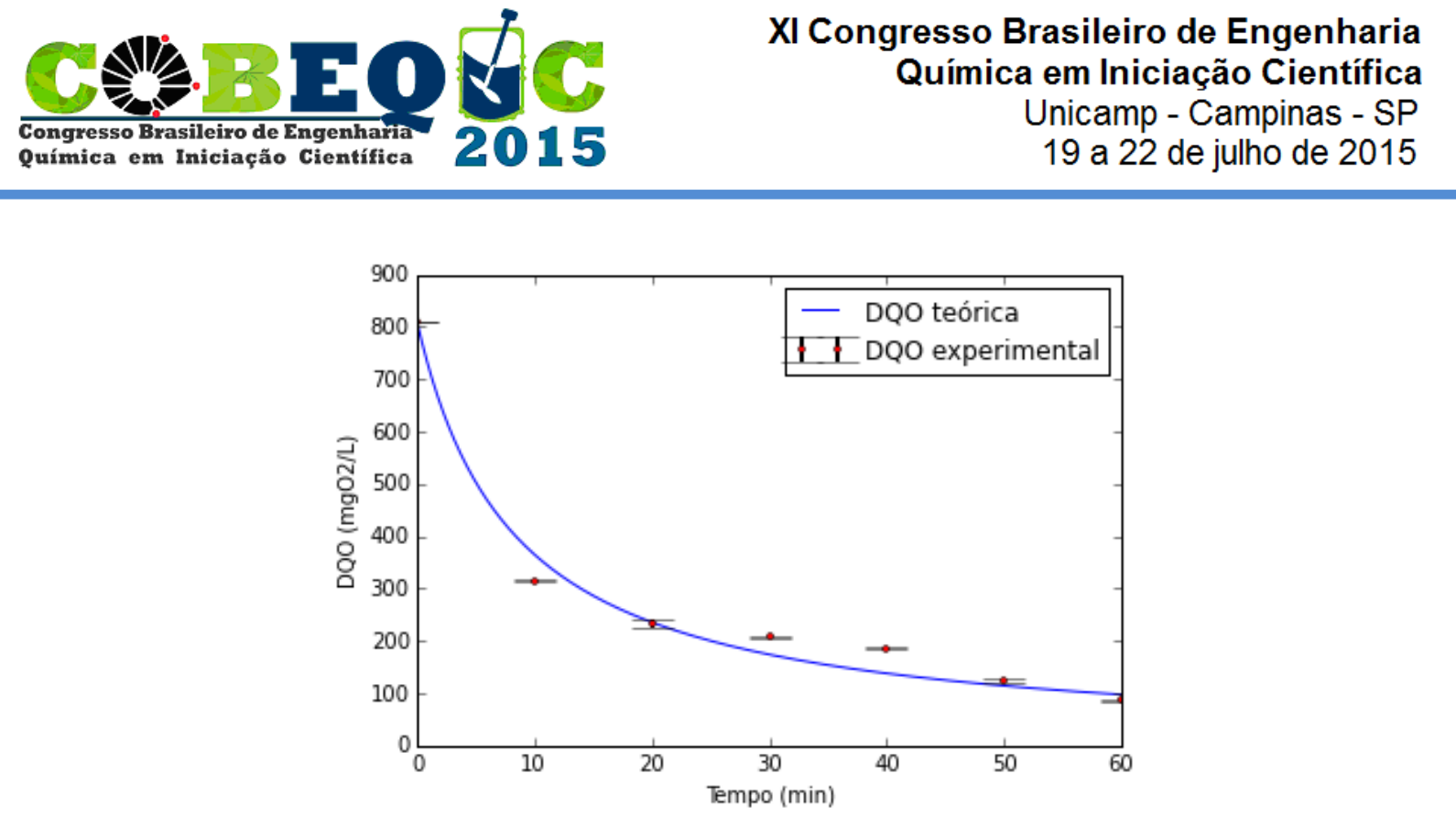

Toma-se como objetivo a obtenção de uma DQO menor que $200 \mathrm{mg} \mathrm{O}_{2} \mathrm{~L}^{-1}$, valor predito pela portaria 154/2002 da SEMACE (Superintendência Estadual do Meio Ambiente do Ceará). Para o atendimento desse requisito, de acordo com a curva teórica, o tempo necessário seria de 25 minutos de tratamento, enquanto que para os pontos experimentais esse tempo seria de 40 minutos. Nota-se que os perfis estão bastante próximos durante os dez primeiros minutos e seguem o formato semelhante no restante do tempo, podendo assim o modelo ser considerado válido. A mudança de comportamento dos pontos experimentais observada entre 25 e 40 minutos pode ser associada à descoloração do efluente nos primeiros 20 minutos de experimento, fato observado na figura 4. Observa-se a redução do pico atribuído à coloração do efluente nos primeiros 20 minutos de tratamento, porém após este tempo de tratamento persiste outras fontes de matéria orgânica como ácidos húmicos e fúlvicos oriundos da água do rio Jaguaruana- CE empregada no tratamento, motivo provável da mudança de comportamento nos pontos experimentais de DQO. O erro também pode ser justificado pela complexidade da análise de DQO, sendo a mesma susceptível a erros experimentais ao longo de suas etapas, desde a lavagem adequada de tubos das amostras até a leitura no espectrofotômetro.

Figura 4 - Redução da coloração ao longo do tratamento

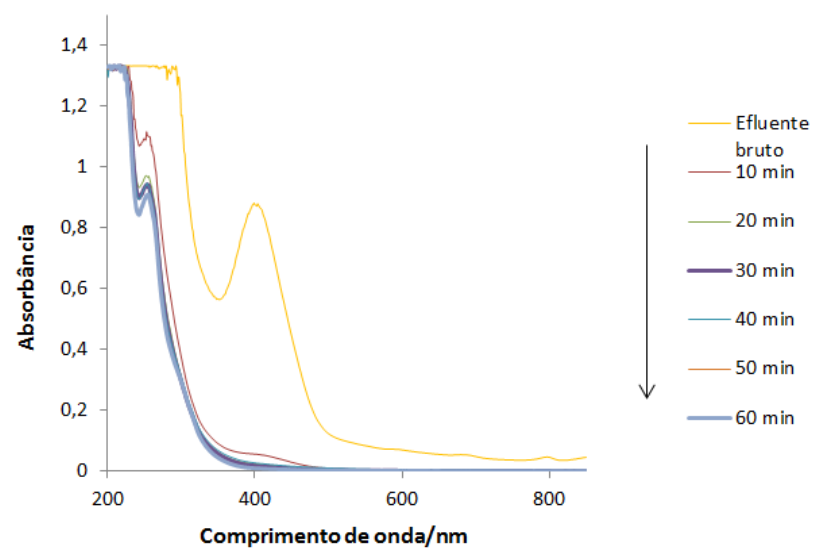

\section{ANÁLISE ECONÔMICA}


A técnica de eletrocoagulação-flotação utilizando corrente contínua pulsada é conhecida por seu baixo custo. No presente trabalho podemos calcular a potência, em Watts, consumida através da equação 6 , onde $U$ é a tensão em volts e i é a corrente em ampères. A tensão para a cidade de Fortaleza é de 220 volts e a corrente empregada no trabalho é 0,409 ampères. Com isso, multiplica-se pelo tempo experimental, em horas, de operação necessário para obter DQO de $200 \mathrm{mg} \mathrm{O}_{2} \mathrm{~L}^{-1}$ e depois divide-se pelo volume de efluente tratado. Sendo o tempo de 0,66 horas e o volume $0,0026 \mathrm{~m}^{3}$. Desse modo, tem-se um resultado de 52,43 $\mathrm{kWh} / \mathrm{m}^{3}$. De acordo com a companhia energética do Ceará (COELCE), o valor do $\mathrm{kW} / \mathrm{h}$ é, em média, $\mathrm{R} \$ 0,40815$. Para o presente trabalho, conclui-se que temos um custo de operação no valor de $\mathrm{R} \$ 21,40 / \mathrm{m}^{3}$.

$$
P=U * i
$$

\section{CONCLUSÕES}

A eficiência do processo de eletrocoagulação-flotação foi comprovada devido a sua remoção de $89,38 \%$ de matéria orgânica em termos de DQO. O reator em batelada em escala de bancada atingiu os objetivos do presente trabalho. A modelagem e simulação do reator permitiu comparar resultados teóricos e experimentais obtendo resultados satisfatórios. Conclui-se que o processo de eletrocoagulação-flotação é uma tecnologia eficiente no tratamento de efluentes têxteis em termos de DQO.

\section{REFERÊNCIAS}

APHA - AWWA - WEF. Standard Methods for the Examination of Water and Wastewater. 21th edition. American Public Health association, American Water Works Association and Water Environment Federation, 2005.

MEDEIROS, A. G. Avaliação dos tratamentos convencional e por oxidação química na degradação de corantes em efluentes têxteis. Dissertação (Mestrado em Engenharia de Processos). Universidade da região de Joinville, UNIVILLE, 2011. 